\title{
Computerized Inventory Systems for Forest Fire Equipment and Personnel
}

\author{
by \\ L. J. Middleton \\ P. H. Kourtz*
}

\begin{abstract}
A computerized inventory system has been designed to meet the equipment control requirements of provincial forest fire management agencies. The system supplies decision-makers with current locations, status and quantities of up to 50 equipment types. Updates and reports are made inexpensively on a regional fire center's remote terminal connected to a remote mini computer. Field testing has been carried out for two fire seasons. Future work will be aimed at developing an inventory control system that integrates district and regional level equipment inventories.

A fire control personnel record keeping program is also described. This program supplies decision-makers with the current availability, experience and work history for up to 500 persons. Over the past 2 years this program has been useful for finding, hiring and paying part-time fire fighting personnel.
\end{abstract}

\section{Résumé}

Un système d'inventaire sur ordinateur a été réalisé pour satisfaire les besoins de contrôle d'équipement des organismes provinciaux de gestion des feux de forêt. Ce système indique aux responsables la situation, la condition et la quantité de quelque 50 sortes d'équipement. Des modifications et des rapports sont faits à peu de frais avec un terminal avancé d'un centre régional contre l'incendie en ligne avec un mini-ordinateur éloigné. Des essais sur le terrain ont eu lieu lors de deux saisons de feu. On va s'attacher dans l'avenir à élaborer un système de contrôle d'inventaire qui regroupera les inventaires d'équipement dans les districts et les régions.

II est aussi question d'une description d'un programme par rapport au personnel de contrôle des feux. Ce programme fournit aux responsables la disponibilité actuelle, l'expérience et le travail accompli par quelque 500 employés. Au cours des deux dernières années, ce programme s'est avéré utile pour localiser, engager et payer le personnel à temps partiel de combat des feux.

\section{Inventory of Fire Control Equipment}

A forest fire management organization controls millions of dollars worth of specialized fire fighting equipment. Within a typical fire management region a major proportion of this

*Computer Programmer and Research Scientist respectively, Forest Fire Research Institute, Canadian Forestry Service, Environment Canada, 240 Bank Street, Ottawa, On tario, K1G 3 Z6. equipment is centrally located at large warehouses while the remaining equipment is located at scattered ranger stations, numerous remote caches, and on initial attack vehicles. In a busy fire situation typically, one or two large fires will have equipment demands that far exceed the local ranger's supply. Equipment must be quickly transferred to the fires from neighbouring caches and warehouses and this equipment may remain at the fire for many weeks. Meanwhile it is particularily important to maintain equipment reserves for new fires that may occur. In a bad situation it is not uncommon to have one or more large "campaign" fires burning while at the same time have 10 to 30 new fires each day. Under these circumstances severe strains are placed on the manual procedures for keeping track of the equipment. Often the system fails when it is needed the most.

Difficulties in record keeping result when transfers of large quantities of equipment take place either into or out of a region. Fire equipment dispatched to a specific fire can be reallocated to either fires or depots without returning to the original inventory location. In the heat of a fire situation paperwork associated with inventory record keeping is often abandoned. Poor inventory control coupled with the high value of equipment leads to mysterious disappearances of items such as radios, chain saws, pumps and camping equipment. More important, the lack of current inventory status information can lead to poor dispatching and delayed calls for mutual aid assistance.

In 1973, the Forest Fire Research Institute began to investigate the problems associated with implementing a computerized fire equipment inventory system. Computer programs were designed to handle the inventory status of two or more Ontario Ministry of Natural Resources regions and corresponding districts (Maloney and Middleton, 1975). The addition, deletion and movement of equipment (updates) in each district were recorded and communicated to the regions daily. The regions then entered the district and regional updates using a remote computer terminal coupled to the Institute's mini computer. Reports were taken by the regions and passed on as requested, to both the district and regional fire control staff. The provincial headquarters also had report taking privileges.

This system was field tested for two fire seasons and while the programs performed their functions, it was clear that before a computerized system could be built, the problems in the existing manual systems had to be cleared up. Implementation attempts pointed out the need for standardized equipment names and processing procedures.

Based on the experience gained with the region district inventory program, it was decided to try a simpler ap- 
proach that involved only the inventory controlled by a single region. Two separate regions were selected for the trials; the fire service centres of the North Central Region of Ontario (Thunder Bay) and the Société de Conservation de l'Outaouais (SCO) (Maniwaki, Quebec). Much of the fire equipment, in both these regions, is centrally located in large warehouses. The manual inventory control procedures for these regions were studied and modified to improve the ease of equipment control. The new regional-level inventory computer program was field tested for another two fire seasons. During this two year trial most remaining procedural problems were cleared up and a standard computer inventory system emerged. Both the OMNR and SCO are now using the system on an operational basis.

\section{Details of the Inventory Programs and It Use}

As a result of the field tests, the two operational versions of the inventory program have evolved into roughly the following format. Two inventory data files are maintained. One is tabular and records the number of units of each equipment category (presently 20 to 50 categories) that are located at each location (i.e. warehouses by status levels, districts, fires). The other file is a list of individual equipment units by serial numbers. Units of three to five equipment categories (i.e. power pumps, power saws, radios) have been kept on this list. The tabular file indicates to the user the number of pumps at a location and the list file indicates which pumps they are. The program provides both a flexible reporting facility allowing for full, partial or single item reports and an easy to use updating facility.

The program resides on the Institute's Digital PDP 11/T34 mini computer which runs under a RSX-11M operating system. The program was written in FORTRAN IV and interactively prompts the users for report requests and updates. The data files occupy 5000 words of disk storage and the program has been overlayed allowing it to run in a 25000 word memory partition. Access from the fire service centres is via 300 Baud lines and Digital LA36 terminals.

During a typical day at a fire centre the program is run from one to four times. The user may query, add, delete or modify entries in the database. The approximate cost of operating the systems for a five month period is $\$ 775$. This figure does not include the salary of a terminal operator and it assumes the inventory is only responsible for fifteen $\%$ of the terminal and communication utilization. The cost will vary, as the percentage of utilization goes up or down. For example, if the inventory was the only program to utilize the remote terminal (\$150/month) and the communication line (\$315/month) the cost for the same five month period would be about $\$ 2750$.

The cost of computer resources was figured to be about $\$ 425$ for the entire five month period. This figure was derived by writing the cost of an $\$ 80000$ mini-computer off. over a five-year period and assigning an hourly charge for the computer resource usage. During the 1978 fire season, between May 1, and September 31, the fire centre at Thunder Bay accessed the inventory program about two hundred times using a total of fifty-five hours of computer resources.

\section{Future Developments in Inventory Control}

Work has already begun on developing a combined region-district inventory system where a computer terminal in each district will be used to participate directly in the region's inventory system. A latter stage, yet to be designed, will involve the linking of many regions together to provide province-wide inventory information.

Audit trails permitting the retracing of the movement history of equipment could be easily incorporated into the existing system. Investigations have begun into the role of various devices, to facilitate data capture and entry such as portable devices with bar code or mark sensing read capabilities. In the more distant future linkups between inventory programs and other decision-making aids such as resource allocation and accounting programs will be feasible.

\section{Computerized Personnel Record Keeping}

The SCO fire control organization operates with a skeleton staff of about 15 permanent personnel throughout the winter. During the fire season about 35 seasonal employees are added. As a fire situation develops more people quickly must be hired on a temporary basis. In 1976, a fire situation developed that required the hiring of 600 additional people over a period of several weeks. The Institute has developed a personnel record keeping computer program to assist in finding, hiring, and paying part-time personnel. For details see "User's Manuals for Forest Fire Control Equipment Inventory and Personnel Programs"' (Middleton, 1977).

The program presently can handle a maximum of five hundred records. As each employee is hired, a record is created in the data file via a remote terminal to the Institute's computer. The record contains the following information: name, address, phone number, social insurance number, fire experience, work classification, driving qualifications, personal fire fighting equipment, current work status and the current year's work history. The record is updated every time a change in the employee's work status occurs during the fire season. This results in the employee's work history for the fire season being recorded.

The program provides a good reporting facility to obtain various aspects of the information in the data file. The user may obtain a full report giving the entire contents of every record in the data file. An availability report prints out all personnel available to fight fires. This report may be stratified by job classification and ability rating. A status report may be obtained for a specific individual or for the personnel working on a specific fire or on all fires. Given a starting and ending date, the program produces a list of all personnel who were assigned to a fire during that time period.

The personnel program was implemented with little or no problems and has been field tested for two fire seasons. It was originally designed to provide fire managers with availability and qualification information about their seasonal fire fighting personnel but several other side benefits have been derived as well. The program provides the payroll section with a double check with regards to which personnel to pay and the accounting section with a history of the personnel who worked each fire thus providing valuable information when assigning costs to individual fires. Future developments with this program will be aimed at integrating the personnel database with various administrative functions such as payroll and accounting and with future resource allocation models.

It appears that many fire control organizations can use the equipment inventory and personnel programs as stand alone tools. However it should be kept in mind, that the greatest benefits from such systems are derived when they are interfaced with other programs and a comprehensive database established in which information from all sectors of the fire management organization can be tied together and cross related. It is in this way that a computerized system can be of the most benefit in the fire control organization.

\section{References}

Maloney, J. E. and L. J. Middleton, September, 1975: The Two Level Equipment Inventory Program. Information Report F-X-55. Middleton, L. J. February, 1977: User's Manuals For Forest Fire Control Equipment Inventory and Personnel Programs. Information Report FF-X-63. 